\title{
The Statistical Analysis of Implied Parameters for Derivatives Pricing
}

\author{
Yuan Yang \\ Chongqing College of Finance economics, CHINA \\ 13081040660@163.com
}

Keywords: project, risk-free, approach

\begin{abstract}
This project examines estimation of two unconditional implied parameters of diffusion market models across different strike prices of options. The standard implied volatility is conditional on the future movements of average risk-free interest rate. Both of implied volatility and implied average risk-free interest rate are unknown and required to be calculated. However, the unconditional implied volatility and implied average risk-free interest rate can be found by solving a system of two equations. Then, the various volatility similes or skews can be generated under this approach. Furthermore, it examines the implied parameters and volatility smiles or skews by extracting the historical data from market.
\end{abstract}

\section{Introduction}

Option pricing model establishes a relationship amongst the traded derivatives, underlying asset and market variables. Implied volatility, as the key gauge of options prices, is used for financial ETF's at-the-money options expiring in the specific time. The simplest financial derivative (option) is European option. Black-Scholes Merton model is widely used in pricing and hedging European-style options by most of practitioners over the last two decades.

According to the original Black-Scholes Merton model, the volatility implied by the theoretical option price should be constant across all values of strikes. This model takes into account both risk-free asset and risky asset, and calculates a theoretical option price based on the dynamics of an underlying derivative with a constant level of volatility. However, a natural generalization is to model volatility under a stochastic process. For incomplete markets, the basic pricing model is Risk-Neutral Valuation, which the option price is given as the expected value of its future payoff with respect to a risk-neutral measure discounted back to the present time $t$ (Cox and Ross (1976)).

Most of investors are looking for strategies to protect against their potential cataclysmic losses. In such optimal situation, the smaller volatility may be appropriate to take into valuations. In reality, the volatility process cannot be observed directly. The recent evidence suggests that a constant volatility is not adequate (Shimko (1993)). Black-Scholes Merton formula on real market data sets supports the notion of asymmetry with stock prices as well as dependence on time to expiration. Collectively, such dependence is often referred to volatility smiles or skews. Black-Scholes Merton model gives unbiased estimation for at-the-money option, and it gives a systematic error for in-the-money and out-of-money option (Dokuchaev (2006)). There is a gap between historical volatility and implied volatility that generates volatility smiles or skews (Black and Scholes (1972)).

In this project, we will use a simple model with random volatilities and risk-free interest rates to generate various volatility smiles or skews. Also, by comparing to the historical market data, we test any consistency between the historical volatilities and the implied volatilities obtained from our underlying model. The main goal of this project is to model volatility smiles or skews. ONLY European options will be considered in this project.

The following sections will involve as follows:

- Section 2 definitions \& models: it briefly describes the required definitions and models in this project;

- Section 3 experiments \& results: it utilizes sensitivity experiments on the theoretical parametric Black-Scholes Merton formula and analyzes the outcomes with corresponding figures;

- Section 4 historical data analysis: it applies the underlying model into real market data and 
analyzes any consistency between the theoretical volatilities and real volatilities;

- Section 5 further discussion \& conclusion; it demonstrates both importance and causes of volatility smiles or skews in derivatives pricing and an overall summary covered the entire project;

- Next Section is Reference Lists;

- Final Section is Appendix: it includes some figures drawn from experiments \& results as well as Matlab program (See Appendix A12) will be attached in the end of project.

\section{Definitions \& Models}

\subsection{Market Model}

This project considers the diffusion model of a securities market, and it consists of a risk-free asset $\left(B_{t}, t \geq 0\right)$ and a risky asset $\left(S_{t}, t \geq 0\right)$.

Let the stochastic process $\left\{S_{t}, t \geq 0\right\}$ satisfy the following stochastic differential equation:

$$
\mathrm{dS}_{\mathrm{t}}=\mathrm{A}_{\mathrm{t}} \mathrm{dt}+\mathrm{Y}_{\mathrm{t}} \mathrm{dW}
$$

Hence, stochastic volatility model of stock price $S$ is

$$
\mathrm{dS}_{\mathrm{t}}=\mathrm{S}_{\mathrm{t}} *\left(\mathrm{a}_{\mathrm{t}} \mathrm{dt}+\sigma_{\mathrm{t}} \mathrm{dW} \mathrm{t}\right), \mathrm{t}>0
$$

Where: $\sigma_{t}$ is the Coefficient of Volatility Process; $\mathrm{W}_{\mathrm{t}}$ is a Geometric Brownian Motion Process; $a_{t}$ is an Appreciation Rate; $S_{0}$ is Initial Price of risky asset at a given deterministic level and $S_{0}>0$.

The price of Risk-Free asset is

$$
\mathrm{B}_{\mathrm{t}}=\mathrm{B}_{0} * \exp \left(\int_{0}^{\mathrm{t}} \mathrm{r}_{\mathrm{s}} \mathrm{ds}\right)
$$

Where: $r_{s}$ is a random process and $r_{s} \geq 0 ; B_{0}$ is Initial Price of risk-free asset at a given deterministic level.

\subsection{Black-Scholes Merton Formula for European Options}

The following notations will be applied for Black-Scholes Merton formula:

- $\quad \mathrm{t}$ is the current time;

- $\mathrm{S}_{\mathrm{t}}$ is the underlying share price at time $\mathrm{t}$;

- $\mathrm{K}$ is exercise price;

- $\quad \mathrm{T}$ is option expiry date, $\mathrm{T}>\mathrm{t}$;

- $\mathrm{C}_{\mathrm{t}}$ is price at time $\mathrm{t}$ of a European call option;

- $\mathrm{P}_{\mathrm{t}}$ is price at time $\mathrm{t}$ of a European put option;

- $\mathrm{r}$ is risk-free continuously-compounding rate of interest;

- $\mu$ is drift of the share;

- $\sigma$ is volatility of the share.

The following assumptions will be applied for Black-Scholes Merton formula:

- The price of the underlying share follows a geometric Brownian motion with constant drift and volatility. Drift measures the average growth of the underlying share, while volatility measures the standard deviation of returns.

- Frictionless markets: There are no transaction costs or differential taxes, and borrowing or short-selling are allowed without restriction.

- The short term interest rate is known and constant in time.

- Stock pays no dividends or other distributions during the life of option.

- Markets are efficient: People cannot consistently predict the movements of the market or individual stock.

- The returns of the underlying stocks are log-normally distributed, which is reasonable for most of stocks to offer options.

- It is a European-style option, which means that the option can only be exercised at the day of expiration.

The value of a European call option at time $t(t<T)$ is

$$
\mathrm{C}_{\mathrm{t}}=\mathrm{f}\left(\mathrm{t}, \mathrm{S}_{\mathrm{t}}\right)
$$




$$
\begin{gathered}
=\mathrm{S}_{\mathrm{t}} \phi\left(\frac{\ln \left(\mathrm{S}_{\mathrm{t}} / \mathrm{K}\right)+(\mathrm{T}-\mathrm{t})\left(\mathrm{r}+\frac{\sigma^{2}}{2}\right)}{\sigma \sqrt{\mathrm{T}-\mathrm{t}}}\right)-\mathrm{K} \mathrm{e}^{-\mathrm{r}(\mathrm{T}-\mathrm{t})} \phi\left(\frac{\ln \left(\mathrm{S}_{\mathrm{t}} / \mathrm{K}\right)+(\mathrm{T}-\mathrm{t})\left(\mathrm{r}+\frac{\sigma^{2}}{2}\right)}{\sigma \sqrt{\mathrm{T}-\mathrm{t}}}-\sigma \sqrt{\mathrm{T}-\mathrm{t}}\right) \\
=\mathrm{S}_{\mathrm{t}} \phi\left(\mathrm{d}_{1}\right)-\mathrm{K} \mathrm{e}^{-\mathrm{r}(\mathrm{T}-\mathrm{t})} \phi\left(\mathrm{d}_{2}\right),
\end{gathered}
$$

Where:

$$
\mathrm{d}_{1}=\frac{\ln \left(\mathrm{S}_{\mathrm{t}} / \mathrm{K}\right)+(\mathrm{T}-\mathrm{t})\left(\mathrm{r}+\frac{\sigma^{2}}{2}\right)}{\sigma \sqrt{\mathrm{T}-\mathrm{t}}} \text { and } \mathrm{d}_{2}=\mathrm{d}_{1}-\sigma \sqrt{\mathrm{T}-\mathrm{t}}
$$

The Proof of European call option under Black-Scholes Merton derivatives pricing formula is shown in Appendix A1.

According to put-call parity, European put option at time $\mathrm{t}(\mathrm{t}<\mathrm{T})$ can be found as

$$
\mathrm{P}_{\mathrm{t}}=\mathrm{C}_{\mathrm{t}}-\left(\mathrm{S}_{\mathrm{T}}-\mathrm{K}\right) * \exp (-\mathrm{r} *(\mathrm{~T}-\mathrm{t}))
$$

\subsection{Random (Stochastic) Volatility}

There are many stochastic models for implied volatilities. For example, the general Hull-White model (Hull and White (1996)) has following dynamics

$$
\begin{aligned}
& d S_{t}=S_{t} *\left(a_{t} d t+\sigma_{t} d W_{t}\right) \\
& d Y_{t}=Y_{t} *\left(b d t+c d V_{t}\right)
\end{aligned}
$$

Where: Volatility is given by $\sigma_{\mathrm{t}}=\mathrm{f}\left(\mathrm{Y}_{\mathrm{t}}\right), \mathrm{f}(\mathrm{y})=\sqrt{\mathrm{y}}, \mathrm{b}<0, \mathrm{~W}$ is uncorrelated to $\mathrm{V}$.

Meanwhile, many alternative models also may be applied. Since, Hull-White model looks too complicated to study. We just consider a toy (simpler) model. Here a special case will be studied where volatility can only take on two values. For instance, jump between high and low volatility. It is assumed that the volatilities are uncorrelated, which is $\rho=0$. This means that under the risk-neutral probability measure $\mathrm{Q}$ the volatility is uncorrelated with $\mathrm{W}_{\mathrm{t}}$.

In the case, call option price can be shown as

$$
\mathrm{C}(\mathrm{t}, \mathrm{S}, \mathrm{y})=\mathrm{E}^{(\gamma)}\left[\mathrm{C}_{\mathrm{BS}}\left(\mathrm{t}, \mathrm{S}, \mathrm{K}, \mathrm{T}, \sqrt{\overline{\sigma^{2}}} \mid \mathrm{Y}_{\mathrm{t}}=\mathrm{y}\right)\right]
$$

Where: $Y_{t}$ is NOT a Markov process (constant) with two states. $\overline{\sigma^{2}}=\frac{1}{T-t} \int_{t}^{T} f\left(Y_{s}\right)^{2} d s$, which is a stochastic variable. It is shown by Renault and Touzi (1996) that stochastic volatility of European option prices produces a smile curve for any volatility process uncorrelated with the Brownian motion driving the price process. The $\overline{\sigma^{2}}$ is a Bernoulli variable under the risk-neutral measure $Q^{(\gamma)}$.

$$
\begin{gathered}
\overline{\sigma^{2}}=\sigma_{1}{ }^{2} \text { with probability } \mathrm{p}, \\
=\sigma_{2}{ }^{2} \text { with probability } 1-\mathrm{p} .
\end{gathered}
$$

Now, by applying the martingale pricing will give that

$$
\mathrm{C}_{\mathrm{BS}}(\mathrm{K} ; \mathrm{I}(\mathrm{p}, \mathrm{K}))=\mathrm{p}^{*} \mathrm{C}_{\mathrm{BS}}\left(\mathrm{K} ; \sigma_{1}\right)+(1-\mathrm{p})^{*} \mathrm{C}_{\mathrm{BS}}\left(\mathrm{K} ; \sigma_{2}\right)
$$

Where: $\mathrm{C}_{\mathrm{BS}}$ is the standard Black-Scholes Merton formula.

\subsection{Unconditionally Implied Parameters}

The standard definition of implied volatility at time $t$ is conditional on future movements of risk-free interest rate $r_{s}$, where $s \in[t, T]$. However, risk-free interest rate is unknown and required to predict in reality. Because of the price of option depends on future forward rate. Then, the pair of unconditionally implied parameters $\left(\sigma_{\text {imp }}(t), \rho_{\text {imp }}(t)\right)$ can be inferred from a system of two equations for different options (Dokuchaev (2006)). This pair will be shown that

$$
\begin{aligned}
& \mathrm{H}_{\mathrm{BS}}^{(1)}\left(\mathrm{t}, \mathrm{S}(\mathrm{t}), \sigma_{\text {imp }}(\mathrm{t}), \rho_{\text {imp }}(\mathrm{t})\right)=\mathrm{P}^{(1)}(\mathrm{t}), \\
& \mathrm{H}_{\mathrm{BS}}^{(2)}\left(\mathrm{t}, \mathrm{S}(\mathrm{t}), \sigma_{\text {imp }}(\mathrm{t}), \rho_{\text {imp }}(\mathrm{t})\right)=\mathrm{P}^{(2)}(\mathrm{t}) .
\end{aligned}
$$

Where: $\sigma_{\text {imp }}(t)$ is the implied volatility $\rho_{\text {imp }}(t)$ is the implied average forward risk-free interest rate.

\section{Experiments \& Results}

\subsection{Two European Call options with Different Strike Prices}

Firstly, our experiments start with two European call options with different strike prices. Assume two European call options have market prices $\mathrm{P}_{1}(\mathrm{t})$ and $\mathrm{P}_{2}(\mathrm{t})$ on the same stock at time $\mathrm{t}$. By 
ignoring the time effect, it is assumed that both of options have the same expiration time $(\mathrm{T}>0)$ and different strike prices $\left(\mathrm{K}_{1}>0, \mathrm{~K}_{2}>0\right)$.

A system of two equations can be set up as:

$$
\begin{aligned}
& \mathrm{H}_{\mathrm{BS}, \mathrm{c}}\left(\mathrm{t}, \mathrm{S}(\mathrm{t}), \sigma_{1}\left(\mathrm{t}, \mathrm{K}_{1} \mid \rho\right), \rho, \mathrm{K}_{1}\right)=\mathrm{P}^{(1)}(\mathrm{t}), \\
& \mathrm{H}_{\mathrm{BS}, \mathrm{c}}\left(\mathrm{t}, \mathrm{S}(\mathrm{t}), \sigma_{1}\left(\mathrm{t}, \mathrm{K}_{1} \mid \rho\right), \rho, \mathrm{K}_{2}\right)=\mathrm{P}^{(2)}(\mathrm{t}) .
\end{aligned}
$$

Assume $\hat{\rho}=\hat{\rho}\left(K_{1}, K_{2}\right)$ is a solution of above formula. Then, we have $\left(\sigma_{\text {imp }}(\mathrm{t}), \rho_{\mathrm{imp}}(\mathrm{t})\right)=\left(\sigma_{1}\left(\mathrm{t}, \mathrm{K}_{1} \mid \hat{\rho}\left(\mathrm{K}_{1}, \mathrm{~K}_{2}\right)\right), \hat{\rho}\left(\mathrm{K}_{1}, \mathrm{~K}_{2}\right)\right)$ (Dokuchaev (2006))

As an example, one may consider the case when $\mathrm{t}=0, \mathrm{~T}=1, \mathrm{p}=0.5, \mathrm{~S}_{0}=1, \sigma_{1}=0.3, \sigma_{2}=0.7$, $r_{1}=0.01, r_{2}=0.08$. The result is shown on Appendix A2.

\subsection{Sensitivity Analysis based on Two European Call options}

\subsubsection{By changing initial price $S_{0}$ and remaining all the other parameters constant}

For example, we consider the case when $\mathrm{t}=0, \mathrm{~T}=1, \mathrm{p}=0.5, \mathrm{~S}_{0}=3, \sigma_{1}=0.3, \sigma_{2}=0.7, \mathrm{r}_{1}=0.01$, $\mathrm{r}_{2}=0.08$. The only change is initial price $S_{0}$ increases from 1 to 3 . The result is shown in Appendix A3. Clearly, any change in current stock price will produce the similar shape as initial situation.

\subsubsection{By changing Probability $p$ and remaining all the other parameters constant}

For instance, we consider the case (A4) when $\mathrm{t}=0, \mathrm{~T}=1, \mathrm{p}=0.75, \mathrm{~S}_{0}=1, \sigma_{1}=0.3, \sigma_{2}=0.7$, $\mathrm{r}_{1}=0.01, \mathrm{r}_{2}=0.08$; or the case (A5) when $\mathrm{t}=0, \mathrm{~T}=1, \mathrm{p}=0.25, \mathrm{~S}_{0}=1, \sigma_{1}=0.3, \sigma_{2}=0.7, \mathrm{r}_{1}=0.01$, $r_{2}=0.08$. The only change is Probability p moves from 0.5 to 0.75 and 0.25 respectively. The result is shown in Appendix A4 \& A5. No matters the probability raises or reduces, the charts still have similar implied volatility surfaces by comparing to initial situation.

\subsubsection{By changing Maturity Time T and remaining all the other parameters constant}

For example, we consider the case when $\mathrm{t}=0, \mathrm{~T}=3, \mathrm{p}=0.5, \mathrm{~S}_{0}=1, \sigma_{1}=0.3, \sigma_{2}=0.7, \mathrm{r}_{1}=0.01$, $r_{2}=0.08$. The only change is Maturity time of both options varies from 1 to 3 . The result is shown in Appendix A6. Again, similar shape is shown as before.

3.2.4 Two European call options at given level of volatility with different interest risk-free rates

As an example, one may consider the case when $\mathrm{t}=0, \mathrm{~T}=1, \mathrm{p}=0.5, \mathrm{~S}_{0}=1, \sigma_{1}=0.3, \sigma_{2}=0.3$, $r_{1}=0.01, r_{2}=0.08$. The only change is both options have equally volatility. The result is shown in Appendix A7. In this case, we could find out the volatility skews instead of volatility smiles.

3.2.5 Two European call options at given level of risk-free rate with different volatilities

For instance, we consider the case when $\mathrm{t}=0, \mathrm{~T}=1, \mathrm{p}=0.5, \mathrm{~S}_{0}=1, \sigma_{1}=0.3, \sigma_{2}=0.7, \mathrm{r}_{1}=0.01$, $r_{2}=0.01$. The only change is both options have equally risk-free interest rate. The result is shown in Appendix A8. Similar shape is shown as initial case.

\subsubsection{Two European call options at different Maturity Time T}

For instance, we consider the case when $\mathrm{t}=0, \mathrm{~T}_{1}=1, \mathrm{~T}_{2}=3, \mathrm{p}=0.5, \mathrm{~S}_{0}=1, \sigma_{1}=0.3, \sigma_{2}=0.7, \mathrm{r}_{1}=0.01$, $\mathrm{r}_{2}=0.08$. The only change is making unequally Maturity times of two options. The result is shown in Appendix A9. Different shape is presented by comparing to initial one. Due to the real volatility is time dependent random variable.

\subsection{Extension to Two European put options with Different Strike Prices}

Under the same conditions, the implied volatility of two European Put options has an opposite direction compares to two European Call options. As an example, one may consider the case when $\mathrm{t}=0, \mathrm{~T}=1, \mathrm{p}=0.5, \mathrm{~S}_{0}=1, \sigma_{1}=0.3, \sigma_{2}=0.7, \mathrm{r}_{1}=0.01, \mathrm{r}_{2}=0.08$. The result is shown in Appendix A10.

\section{Historical Data Analysis}

In this project, we would like to employ the historical Skandia and BHP call options data for our analysis. Both of them are extracted from S\&P 500 stock market exchange and on the same date of $24^{\text {th }}$ September 2010 . We are going to test any consistency between real volatilities and implied volatilities obtained from our underlying model. All the data are shown below in Appendix A11 (a).

We can work out the risk-free rate of interest by using Black-Scholes Merton formula with all the information are given (eg. current price of stock, time to maturity, strike prices, option prices, and 
real (implied) volatility are known). The underlying model adopted in this project is to set up a system of two equations. Then, we can solve a pair of unknown parameters $\left(\sigma_{\text {imp }}(t), \rho_{\text {imp }}(t)\right)$ from a system of equations. Any hypothesis is not needed in our model.

We are able to solve such problem by using Matlab. Then, the equation is shown as follows,

$$
\mathrm{H}_{\mathrm{BS}, \mathrm{c}}\left(\mathrm{S}_{0}, \sigma_{\mathrm{imp}}, \rho_{\mathrm{imp}}\right)=(\mathrm{Bid}) \text { price of Call option }
$$

Where: $S_{0}$ is current stock price and is known, $\sigma_{i m p}$ can be observed from historical option data, $\rho_{\text {imp }}$ is unknown parameter, which we wish to calculate.

With respect to option on Skandia stock, the risk-free interest rates can be calculated as constant value at 0.035 (See Appendix A11 (a) (1)) across all levels of strikes. Nothing surprising, this outcome is which we expect to get. To calculate the price of European option standard by using Black-Scholes Merton model, it requires some hypothesis about risk-free interest rates. We have to make adjustments of risk-free interest rates at some given values before calculations. For instance, we may use a 10 years US Treasury bond yield as our risk-free interest rate. In this case, the yield of 10 years US Treasury bond yield (See Appendix A11 (b)) on the date of $24^{\text {th }}$ September 2010 is given at 0.035 , which is the same as the risk-free yield obtained in our model. The result is reasonable and consistent to illustrate either volatility smiles or volatility skews for both the real volatility and the implied volatility at some given level of risk-free interest rate.

However, there is inconsistent result in calculating the rate of risk-free interest for option on BHP stock. At the moment, the risk-free interest rates are calculated as a vector of different values (See Appendix A11 (a) (2)) across all levels of strikes. This is an unexpected scenario. Since, Black-Scholes Merton model assumes that both risk-free interest rate and volatility of underlying stock price remain constant over the period of analysis. Theoretically, Black-Scholes Merton model can work appropriately if all its assumptions hold. To determine risk-free interest rate by using Black-Scholes Merton formula, all the (bid) price of option, current stock price, time to maturity, strike prices, and the observed volatility may affect risk-free interest rate. One explanation may state that Black-Scholes Merton model must yield call option prices which exceed the observed market prices for the out-of-money options and call option prices which are less than the observed market prices for the in-the-money options (James and Larry (1979)). Because of the implied volatilities decline as the option exercise prices increase. For instance, let us consider that options of BHP stock traded on $24^{\text {th }}$ September 2010. For the case of in-the-money, options may have the observed market prices greater than Black-Scholes Merton model option prices. While, for the case of out-of-money, options may have the observed market prices less than Black-Scholes Merton model option prices. This may cause small difference of risk-free interest rates across different strike prices at all the given information, when we employ Black-Scholes Merton formula into calculation.

Likewise, there may also be some other possible explanations are listed as follows:

- Nature of business,

- Imperfect market or information asymmetric,

- Over- or under- market reactions,

- Expectations of speculation,

- Gap between the observed volatility and the true implied volatility.

Any of above reasons will shift the behavior of investors, which means the observed market (bid) price of option will move far away to its true value (under theoretical model). Meanwhile, it indicates that Black-Scholes Merton model does not always work perfectly in reality. The range of the calculated risk-free interest rate for options on BHP stock is between 0.0126 and 0.0168 in the case. All of such rates fluctuate around the average risk-free interest rate at 0.014583 . Since, there is not too big difference amongst these risk-free interest rates. Thus, such underlying model in this project is still a good approach to use in reality.

\section{Further Discussion \& Conclusion}

We can see that there are many financial literatures discuss about the implied volatility. 
Unfortunately, it is not easy to find out that why the implied volatility is popular to use for derivatives pricing by most of investors or how the implied volatility works essentially in the financial derivatives.

Let us consider the causes of volatility smiles or skews from the practical (business) perspectives. This may be an alternative way to see the importance of volatility smiles or skews. In general, volatility smiles or skews may occur by the following causes:

Behavioral Causes:

- Crash protection,

- Demand for protection,

- Expectation of changes in volatility over time,

- Support or resistance levels at various strike prices;

Structural Causes (Violations of Black Scholes assumptions):

- Inability to hedge continuously,

- Transactions costs,

- Local volatility $\sigma(\mathrm{S}, \mathrm{t})$,

- Leverage effect,

- Stochastic volatility,

- Jumps or crashes.

All the rational investors will make their own decisions in derivatives pricing, which is based on the predicted implied volatility and the historical volatility. For instance, volatility smiles or skews are long observed pattern in which at-the-money options tend to have lower implied volatilities than either in- or out- of-money options.

In conclusion, most of practitioners still accept to use Black-Scholes Merton model, as the premier model, to price and hedge of options in recent decade. Ideally, original Black-Scholes Merton model will give us an intuitive knowledge of derivative pricing. However, Black-Scholes Merton model will not work perfectly in practical. Since, there are too many assumptions and restrictions for using Black-Scholes Merton model. Also, real volatility is random and time-varying. Moreover, future implied volatility and future risk-free interest rate are difficult to forecast. In our hypothesis free model, the volatility smiles or skews could be found by solving a system of two equations. The methodology applied in this project should be also useful in reality.

\section{References}

[1] Black, F. and Scholes, M,The valuation of options contracts and test of market efficiency, Journal of Finance, vol. 27,pp. 399-417,1972.

[2] Cox, J. C. and S. A. Ross, The valuation of options for alternative stochastic processes, Journal of Financial Economics, vol.3, pp.145-166,1976.

[3] Dokuchaev, N,Two unconditionally implied parameters and volatility smiles and skews, Journal of Applied Financial Economics, vol.2, pp.199-204,2006.

[4] Hull, John. and White, Alan. (1996) The pricing of options on assets with stochastic volatilities. J. Finance, vol.6(3),pp.279-302,1996.

[5] James, D. M. and Larry, J. M,An empirical examination of the Black-Scholes call option pricing model,Journal of Finance, vol.34(5),pp. 1173-1186,1979.

[6] Renault, E. and Touzi, N,Option hedging and implied volatilities in a stochastic volatility model, Math. Finance, vol.6(3),pp.279-302,1996.

[7] Shimko, D,Bounds of Probability, Risk, pp. 33-37,1993. 